\title{
A Comparative Study on Mental Health Status between Freshmen and Senior Students
}

\author{
Fei Wang
}

Wenshan University, Wenshan, 663000, China

Keywords: Freshmen, Senior students, Mental health, Comparative study

\begin{abstract}
Based on psychological testing, this paper elaborates on the differences of mental health status between freshmen and senior students. It finds that most freshmen are obsessed by disappointment, stress, anxiety, loneliness and confusion because of the contrast between ideal and reality, the inadaptation of college life, the poor performance in interpersonal communication and the loss of life objectives. And most senior students suffer from psychological disorder due to the conflicts in job hunting, employment, postgraduate entrance exams, and affection and so on. It is urgent to take actions to make more college students being in good mental health status. For freshmen, we are required to carry out integrated management and education in line with their psychological characteristics. For senior students, we should center on their employment and provide comprehensive services like job information collection, self-employed promotion so as to help them develop correct values of employment.
\end{abstract}

\section{Introduction}

With respect to previous studies on mental health education of college students, most take all college students as research subjects while few pay attention to the mental health status of students in certain grade. Among those few scholars, some focus on freshmen's adaptability to college life, and some analyzed senior students' employment ${ }^{[1]}$. However, quite few of them have taken comparative study on the mental differences among students in different grades. It is well known that, on one hand, college students share common characteristics in mental health; on the other hand, students in different grades show different mental features because they are on different learning stages, involved with different experiences and faced with different problems ${ }^{[2]}$. Thus, we should not neglect the grade differences of mental health when we carry out psychological health education ${ }^{[3]}$. Through the comparative study of the mental health status of two typical grades, we can find out the psychological characteristics and confusion of college students in different grades, and then provide Psychological guidance for them. As a result, they will realize their own value, eliminate the sense of inferiority and establish self-confidence ${ }^{[4]}$. Through the education of releasing negative emotions, they will speak out their bad feelings, reduce the psychological burden caused by low self-esteem, loss, anxiety and tension, learn to restrain emotions and maintain emotional stability.

\section{Comparative analysis of freshmen's and senior students' mental health status}

This paper will firstly analyze the previous studies on the mental health status of students at different grades. It applies the widely-used international measurement scale of mental health Self-rating Symptom Scale SCL-90 which covers 9 basic symptom factors, 1 additional scale and 90 symptoms. The sub-factor represents the severity of mental disorders. The greater the number, the more serious the symptom is. The data of this study is based on a survey of 1000 freshmen and senior students from 6 colleges in Shandong Province. 
Table 1 SCL-90 symptom factors of freshmen and senior students

\begin{tabular}{|c|c|c|}
\hline SCL-90 symptom factors & Freshmen X \pm SD(n=500) & $\begin{array}{c}\text { Senior students X 士 SD } \\
(\mathrm{n}=500)\end{array}$ \\
\hline Somatization & $1.52 \pm 0.52$ & $1.551 \pm 0.643$ \\
\hline Forced symptoms & $2.042 \pm 0.658$ & $1.915 \pm 0.686$ \\
\hline Interpersonal sensitivity & $1.924 \pm 0.661$ & $1.79 \pm 0.62$ \\
\hline Depression & $1.906 \pm 0.654$ & $1.8 \mathrm{D} 3 \pm 0.643$ \\
\hline Anxiety & $1.669 \pm 0.592$ & $1.592 \pm \mathrm{D} .574$ \\
\hline Hostility & $1.711 \pm 0.703$ & $1.705 \pm 0.678$ \\
\hline Terror & $1.557 \pm 0.574$ & $1.504 \pm 0.64$ \\
\hline Paranoid & $1.835 \pm 0.625$ & $1.823 \pm 0.657$ \\
\hline Mental illness & $1.617 \pm 0.583$ & 1.586 生 0.588 \\
\hline
\end{tabular}

Table 2 T value of SCL-90 symptom factors of freshmen and senior students

\begin{tabular}{|c|c|}
\hline SCL-90 symptom factors & $\begin{array}{c}\text { T value of freshmen and senior } \\
\text { students }\end{array}$ \\
\hline Somatization & -0.699 \\
\hline Forced symptoms & 2.561 \\
\hline Interpersonal sensitivity & 2.992 \\
\hline Depression & 2.213 \\
\hline Anxiety & 1.869 \\
\hline Hostility & 0.101 \\
\hline Terror & 1.172 \\
\hline Paranoid & 0.255 \\
\hline Mental illness & 0.737 \\
\hline
\end{tabular}

The tables above show that the mean value and standard deviation of each symptom factors, except somatization, of freshmen are higher than those of senior students. As for the forced symptoms, interpersonal sensitivity and depression, they have significant variation. But for anxiety, hostility, terror, paranoid and mental illness, they do not have significant variation. 
Table 3 The mental health problems of freshmen and senior students

\begin{tabular}{|c|c|c|}
\hline Compare items & $\begin{array}{c}\text { Freshmen } \\
(500)\end{array}$ & $\begin{array}{c}\text { Senior students } \\
(500)\end{array}$ \\
\hline studying pressure & 40 & 170 \\
\hline Interpersonal discord & 160 & 30 \\
\hline Love problem & 60 & 105 \\
\hline Environmental adaptation & 125 & 0 \\
\hline Employment pressure & 10 & 335 \\
\hline Economic burden & 130 & 105 \\
\hline Neurosis & 65 & 70 \\
\hline Graduate study pressure & 15 & 285 \\
\hline $\begin{array}{c}\text { Perplexity of ideal and } \\
\text { reality }\end{array}$ & 90 & 25 \\
\hline Suicide tendency & 5 & 5 \\
\hline Perplexity of sex & 50 & 15 \\
\hline $\begin{array}{c}\text { Not satisfied with the } \\
\text { profession }\end{array}$ & 75 & 15 \\
\hline
\end{tabular}

According to Table 3, we find that the mental health of freshmen and senior students are different. Freshmen have more problems in environment adjustment, economic, interpersonal communication and major satisfaction while senior students have more problems in employment and graduate study. In general, freshmen's mental health problems are much more serious, which is in line with the above results.

\section{Differences of mental health between freshmen and senior friends}

\subsection{Reasons of freshmen's mental health status}

Based on this research, we conclude that most freshmen are obsessed by disappointment, anxiety, emotional instability and loneliness because of the following reasons.

\subsubsection{Disappointment from the contrast between ideal and reality}

The moment they go to college, most freshmen are faced with the big contrast between ideal and reality mostly in three aspects. They are the contrast between satisfactory living conditions in mind and disappointing real-life conditions, between vivid and lively college life in mind and nervous and boring life in reality, and between success in college in mind and frustrations in reality. Facing these big contrasts, most freshmen gradually lose hope and become depressed. Some even fall into endless despair ${ }^{[5]}$. These all not only suppress their confidence and potential, but also seriously impact their mental health.

\subsubsection{Stress and anxiety from the inadaptability to college study}

For freshmen's inadaptability to college life, we conclude three major reasons. Firstly, they are not ready for the hard work in college. Secondly, they cannot improve their learning methods in line with college study. It is well known that the teaching methods in college is quite different from that in high school. In college class which doesn't completely follow the text book, teachers play the leading role while students are required to digest what they were taught in class after class. In fact, college students have more free time than high school students. That means, they should master the learning methods to listen to teachers carefully, to take notes, to collect information and to manage their time. However, most freshmen still follow the learning methods in high school, and accordingly have difficulty in college learning. Thirdly, they cannot manage their time reasonably. According to this research, we find that some freshmen engage themselves in ball playing, chess, online chatting, games and affection. Above all, the conflict between more autonomy in college and 
freshmen's lack of self-control is the major reason of their inadaptability to college study.

\subsubsection{Emotional fluctuation from the inadaptability to college life}

For most freshmen, it is their first time to leave their parents for a completely new place and start to live independently. There is not doubt that they have difficulty in adjusting to such independent college life. As a result, they prone to being have severe emotional fluctuation.

\subsubsection{Loneliness from the inadaptability to interpersonal communication}

As a college student, freshmen are considered to live independently without parents' thoughtful care. In such a new place distant from home, they either have little experience to make friends or have difficulty in communicate with others honestly. Some are even self-centered. They desire to excel over others, demand others respect and dislike to communicate with others willingly. Once their demand cannot be meet, they will have a grudge against those better than him. Besides, students at this age easily fall into autism. Hence, they will feel lonely and helpless.

\subsection{Reasons of senior students' mental health status}

The mental health problems of senior students are influenced by both the social environment and the college environment. For social environment, the stress from the reform of economic system and politic system has bad effect on college students, especially senior students who are busy in job hunting. For college environment, the special environment in college and the stress of job hunting in the fourth year directly increase the pressure of senior students. Without correct instruction and actions, the pressure above will lead to severe mental problems as follows.

\subsubsection{Conflicts in career choice}

All senior students are required to make career choices like pursuing graduate study, work, and going abroad for further study and so on when they graduate. A correct career choice is very important for their life since it to some extent decide his future life. Some students choose to take postgraduate entrance exam and apply for a job at the same time. However, the limited time and energy may result in the failure of both choices and increases their mental stress.

\subsubsection{Conflicts in employment}

During the process of job hunting, senior students will be faced with many conflicts. The first one is the conflict between job choice and parents' ideas. When they make job choices different from parents, they have to negotiate with parents which make them under great pressure. Besides, the conflict between the ideal job and real job, exactly the ideal job and social need, is striking. For students in Shandong Province, deeply influenced by the idea of bureaucracy, some prefer to be civil servants to glorify their family, some prone to join in foreign companies with high salary. However, the reality is far below their expectations which seriously hurts their confidence and increases their pressure.

\subsubsection{Conflicts in pursuing graduate study}

Students pursuing graduate study bear dual pressure of preparing for postgraduate entrance exam and looking for a job. To make sure they can success in one area at last, they always engage in postgraduate study and job hunting at the same time. However, their limited time and energy decide that they cannot settle down to taking any one of them. These problems and conflicts make them annoyed and anxious.

\subsubsection{Conflicts in affection}

Affection is sweet, but the graduation departure is depressing and cruel. In order to get together, they have to give up something and take additional actions which to large extent increase their mental pressure. 


\section{Conclusion}

There are differences caused by different reasons between the freshmen and the seniors' mental health. Therefore, college education should be in accordance with the mental health status of different grades their cause. At the same time, we should also focus on the common problems of college students and treat them as a whole to carry out education. It will not only improve the effectiveness of education, but also enhance the efficiency of education. Moreover, we should take an integrated management and education to deal with psychological barriers. Mental health education can adjust their bad mood, so that they are willing to accept the ideological and political education and several other aspects of education. On the other hand, through ideological and political education, they will establish a correct world outlook, outlook on life and a firm communist ideal which can prevent mental disorder and t can also make them themselves strong enough to resist the mental harms of bad ideas.

\section{References}

[1] Evaluating the psychometric properties of the mental health Continuum-Short Form (MHC-SF) [J]. Sanne M. A. Lamers, Gerben J. Westerhof, Ernst T. Bohlmeijer, Peter M.ten Klooster, Corey L.M. Keyes. J. Clin. Psychol. 2010 (1)

[2] Best Practices in Conceptualizing and Measuring Social Class in Psychological Research [J]. Matthew A. Diemer, Rashmita S. Mistry, Martha E. Wadsworth, Irene López, Faye Reimers. Analyses of Social Issues and Public Policy. 2013 (1)

[3] Perceived positive teacher-student relationship as a protective factor for Chinese left-behind children's emotional and behavioural adjustment [J]. Yan Liu, Xiaowei Li, Li Chen, Zhiyong Qu. Int J Psychol. 2015 (5)

[4] Depression and anxiety among left-behind children in C hina: a systematic review[J] . J. Cheng, Y.-H. Sun. Child Care Health Dev. 2015 (4)

[5] Evaluation of a Seven-Week Web-Based Happiness Training to Improve Psychological Well-Being, Reduce Stress, and Enhance Mindfulness and Flourishing: A Randomized Controlled Occupational Health Study [J]. T. Feicht, M. Wittmann, G. Jose, A. Mock,E. von Hirschhausen, T. Esch, Stefanie Joos. Evidence-Based Complementary and Alternative Medicine. 2013 